\title{
Three Consciousnesses for Editorial Affairs Staff
}

\author{
Shuhui Wang ${ }^{1, a^{*}}$, Yanping Niu ${ }^{2, b}$, Caijuan Shang ${ }^{3, c}$, \\ Shengfeng Wang ${ }^{4, d}$, Feifei Shang ${ }^{5, e}$ and Jing Luo $0^{6, f}$ \\ ${ }_{1,2,3,4,5.6}$ Department of Scientific Research, Academy of Armored Force Engineering \\ P.R. China, 100072 \\ a *greenleaf999@163.com
}

\section{Keywords: Academic journal; Editorial affairs staff; Three consciousnesses}

\begin{abstract}
The editorial affairs are involved in every aspect of daily work in an editorial department, and they are an indispensable part in the normal operation of a journal. The editorial affairs staff have a deep influence in quality on publishing efficiency, quality and reputation of the journal, and both position and role of editorial affairs should not be neglected. Any one who wants to become an outstanding editorial affairs member should have the consciousness of dedication, responsibility and innovation.
\end{abstract}

\section{Introduction}

There is an increasing fierce competition among editorial departments of academic journals with China's publishing undertaking flourishing [1]. In order to stand out, editorial departments are required to have their own characteristics, high-quality manuscript sources, and high-level editing and processing capacity. Moreover, their editorial affairs staff must be of high quality. A good editorial affairs staff member should be refined and courteous to the outside, offering hospitable services and safeguarding the good image of the editorial department. On the other hand, he or she should be cautious and conscientious to the inside, working hard and guaranteeing all going well in the editorial department.

\section{Overview of Editorial Affairs}

Definition and Content of Editorial Affairs. Just as its name implies, the editorial affair means the transactional management of an editorial department as well as the fundamental work guaranteeing the journal publishing operation. Any editorial department with complete organization and clear division of work should be allocated with the corresponding editorial affairs staff besides a certain number of editors [2]. The editorial affairs staff are a link of readers and authors, the assistants of chief editors and editors, and the support crew of an editorial department. As we all know, the periodical publishing is involved in topic selection, contributions soliciting, manuscript examining, editing \& processing and editorial affairs, of which the editorial affairs are most rarely known. Both editorial affairs staff and editors are equally to serve the periodical publishing. Compared with the latter, the former mostly do the work behind the scene, and their job duties are different depending on the scale, manning quotas and periodical property of an editorial department, generally including collection of manuscripts, register, detection of academic misconducts, sorting and entry of manuscripts examining opinions, statistics and accounting of manuscript examining fees, file archives management, establishment and maintenance of expert and author databases, periodical presentation and publishing, response to author's inquiry on contributions, manuscript scheduling inquiry, letter receiving and posting and external communication and liaison. It is thus seen that editorial affairs staff' duties are trivial and obscure [2]. 


\section{Position and Role of Editorial Affairs}

Although the editorial affairs seem to be some fundamental and auxiliary work, they are involved in every aspect of periodical publishing, and they are an indispensable part of the publishing system. The publishing work is a systematic project, and all links for periodical publishing including manuscript receiving, misconduct detection, preliminary review, external review and contribution acceptance or rejection, as well as payment for late remuneration, distribution of remuneration, presentation of sample issues, periodical distribution, all are a successional and linkable process, and any problem may affect the successful periodical publishing in any link [3,4]. In this process, the editorial affairs staff members undertake a great deal of earlier and later niggling. They should not only handle the internal specific affairs but also take charge of external communication. So their duties directly affect reputation, sources of contributions and circulation of periodical publishing. Generally speaking, the editor is to serve authors, whereas the editorial affairs staff should serve both authors and editors. Clear division of work and mutual supplement of editors and editorial affairs staff can ensure the editors devote their energy to processing and proofreading of contributions. If there were no backup of editorial affairs staff, the editors would have to drain of more energy to handle lots of trivial, and they are mentally and physically exhausted, which is bund to affect edition and proofreading. Thus, right understanding of importance and necessity of editing affairs is a precondition for a good operation of editing and publishing.

\section{Three Consciousnesses for Editorial Affairs}

The editorial affairs job is a post involved in strong work load and trivalities of an editorial department. Anyhow, it may test patience and energy of editorial affairs staff $[5,6]$. So, it is not a casual work. With continuous development of information and digital editing and publishing techniques, the editorial affairs duties are not equal to the simple and kee-jerk labors such as routine errands, odds and ends, and fetch and carry; instead, it is a developing science, and requires be undertook by those who master professional skills and knowledge. Thus, any one who wants to become an outstanding editorial affairs member should have the consciousness of service, learning and innovation.

Service Consciousness. More generally, the service consciousness for editorial affairs staff refers to a concept and desire that they should think themselves into others' minds, and offer conscious and warm services [7,8]. The service is their basic characteristic. The strong or weak service consciousness is closely related to the service quality of the editorial office. The service quality is a big problem that matters internal work of the editorial department orderly as well as its image to the outside. Due to a multitude of things, the editorial department should deal with all kinds of problems every day, for instance, receiving authors and consultations; sometimes, one thing is not yet handled, and the other one comes. In these cases, the editorial affairs staff members get worried and irritated easily, and may be impatient accidently or even indifferent to authors' visit. This may affect authors' active contributions and undermine the reputation of the editorial department. For this reason, the editorial affairs staff should develop their own service consciousness by the following practices: Cultivating their own moral culture and character, adjusting their moods and controlling bad feelings, and thinking about other's feelings in troubles. A man of good more culture never makes others uncomfortable in language no matter how he is busy; Aware of importance of their own work, with responsibility consciousness; especially, in the manner of dealing with people, he shows his personal behaviors as well as a window image of the office. He can make a positive impression on authors, readers and assessors only when he keeps warm and courteous; Adept in summarizing good work methods to improve affairs-handling efficiency. The editorial affairs staff should learn time management and data sorting techniques, simplifying the procedures of register, inquiry, letters and publishing. It is not advisable that if the editorial affairs staff don't respond timely to the author's inquiry about contribution, the author may feel the staff's poor efficiency and bad overall impression of the editorial department. 
Learning Consciousness. The editing work is involved in the entire process of the periodical publishing, and it is very complicated, overloaded and multiple [9.10]. So the editorial affairs members are required to be the "experts" as well as the "versatile persons", who are good at many things and expert in one. Besides their own quite professional knowledge, they also know well the basic knowledge of editing and publishing, computer software operating, national copyright law, archival sorting management and security stipulations. So, the editorial affairs members should pay attention to knowledge accumulation to complete their own duties efficiently, and study hard by the following way hard in their spare time: Study in practice: to be an observant and conscientious person in daily work in every link from the day that a manuscript is received to the date that it is published in the journal. For example, more observations and thinking should be made for the opinions by three Reviews of contributions, editors' manuscript proofreading and English version of abstracts; they seek advice from the experienced editors for unstudied knowledge. By this way, they can accumulate experience and are familiar at the knowledge and skills about editing and proofreading; Study independently in spare time: often subscribing some books and magazines about editing business, archival management and intellectual property, and taking some time to read them and making reading notes as much as possible, so as to improve themselves, expand the scope of knowledge, and promote their own comprehensive quality. Only by this way, they can implement their duties with high proficiency in work; Strive for more train opportunities to the outside for further study. They are hard to take a long time for further study because of busy business, but they may participate in some short-term training classes. From advancement of their business ability, the targeted training is similarly efficient and essential. They should mainly take above-said ways, but it is very important for them to listen to experts' lessons and communicate with peers. By this way, they can contact latest knowledge and thoughts in the publishing industry to expand their field of vision and enhance their task motivation for a long-term development of academic journals.

Innovation Consciousness. Along with developing high technology, many operational modes of traditional editorial affairs are changed gradually into modern ones, such as popularization of current computer network and emergence of WeChat transmission platform, which bring new challenges at the same time of conveniences for editing affairs. In this situation, the editorial affairs staff should keep pace with the times only when they set up the consciousness of innovation; they should get rid of the constraints of inherent old-fashioned concepts, be diligent to thinking and open to new knowledge, explore new skills and brave the traditional problems in editing and publishing by the new thinking methods and working ideas. In the past, the periodical propaganda only appeared in inside front or back covers, and they could be seen only by the readers who subscribed the journal. Most of readers only read body inner texts, and concerned less about inside front or back covers. So it resulted in a small range of popularization. With extensive application of Smart mobile phones, some periodicals have established their own WeChat group and platform, where the editorial affairs staff can release periodical publicity and contributions wanted, improving spread speed and influence of academic journal greatly. Of course, their innovation is reflected in the case that they turn originally boring and arduous work into more interesting and reasonable one9. Nowadays, the collecting and editing platform provides a good platform for the editorial affairs staff to give play to their creativity. As long as mastering the powerful functions and operational approaches of the collecting, editing and contributing system, they can simplify the former tedious procedures such as register for contributions, telephone notification and data statistics, and improve work efficiency greatly. So, the editorial affairs staff can develop the new work situations only based on actual conditions and continuous innovation.

\section{Conclusions}

The editing affairs work is an important part of periodical publishing, and also is foundation and guarantee for successful operation of businesses for an editorial department. The editorial affairs are of importance obviously with increasingly fierce competition in publishing industry. Without the backup, cooperation and help of editorial affairs staff, the reputation, both manuscript source and quality of the journal are certainly affected. The editorial affairs staff should know well their duties, 
develop their consciousness of services, learning and innovation all the time, and offer the editorial department an "overall logistical support" by a highly responsible attitude to promote sound progress of periodical publishing work.

\section{References}

[1] Pedro A. Castillo, Antonio M. Mora, et.al. Hossam Faris,Applying computational intelligence methods for predicting the sales of newly published books in a real editorial business management environment. Knowledge-Based Systems, Volume 115, 1 January 2017, Pages 133-151

[2] Inajara Rotta, Thais Teles Souza, Teresa M. Salgado, et.al. Characterization of published randomized controlled trials assessing clinical pharmacy services around the world . Research in Social and Administrative Pharmacy, Volume 13, Issue 1, January-February 2017, Pages 201-208

[3] Stanley A. Edlavitch. Publishing negative findings and the challenge of avoiding type II errors in studies of suspect teratogens: Example of a recent ondansetron publication. Reproductive Toxicology, Volume 67, January 2017, Pages 125-128

[4] Jeffrey Kay, Muzammil Memon, Darren de SA,et.al. Does the Level of Evidence of Paper Presentations at the Arthroscopy Association of North America Annual Meetings From 20062010 Correlate With the 5-Year Publication Rate or the Impact Factor of the Publishing Journa. Arthroscopy: The Journal of Arthroscopic \& Related Surgery, Volume 33, Issue 1, January 2017, Pages 12-18

[5] Rachel M. Frank, Gregory L. Cvetanovich, Michael J. Collins, et.al. Publication Rates of Podium Versus Poster Presentations at the Arthroscopy Association of North America Meetings 2008-2012. Arthroscopy: The Journal of Arthroscopic \& Related Surgery, Volume 33, Issue 1, January 2017, Pages 6-11

[6] Antonio Perianes-Rodriguez, Javier Ruiz-Castillo. A comparison of the Web of Science and publication-level classification systems of science. Journal of Informetrics, Volume 11, Issue 1, February 2017, Pages 32-45

[7] Allysha C. Maragh-Bass, Jessica R. Appelson, Navin R. Changoor, et.al. Prioritizing qualitative research in surgery: A synthesis and analysis of publication trends. Surgery, Volume 160, Issue 6, December 2016, Pages 1447-1455

[8] Carla Curado, Paulo Lopes Henriques, Mírian Oliveira, et.al. A fuzzy-set analysis of hard and soft sciences publication performance. Journal of Business Research, Volume 69, Issue 11, November 2016, Pages 5348-5353

[9] Tiago S. Jesus. Systematic Reviews and Clinical Trials in Rehabilitation: Comprehensive Analyses of Publication Trends. Archives of Physical Medicine and Rehabilitation, Volume 97, Issue 11, November 2016, Pages 1853-1862.e2

[10] Brenda E. Thiel, Candice L. Garwood, Lisa Binns-Emerick. Pharmacy resident research: Improving publication potential and simultaneously identifying intangible gains in the process. Currents in Pharmacy Teaching and Learning, Volume 8, Issue 6, November-December 2016, Pages 920-923 